\title{
Dispositivo midiático de participação nas interações transmídias: explorando o conceito a partir das ações da Rede Globo no seriado Malhação ${ }^{1}$
}

\author{
Yvana Fechine \\ Diego Gouveia Moreira
}

Resumo: A transmidiação é um modelo de produção orientado pela distribuição em distintas mídias e plataformas tecnológicas de conteúdos associados entre si e cuja articulação depende do engajamento proposto ao consumidor. As ações transmídias dependem da disposição do público para, de um lado, buscar e correlacionar os conteúdos midiáticos e, de outro, comentar, compartilhar e intervir diretamente nos produtos ofertados em diferentes plataformas. A participação proposta pelo projeto transmídia precisa, no entanto, estar alinhada com determinados objetivos comunicativos e corporativos. Para que suas estratégias tenham êxito, os produtores transmídias buscam influenciar o público e manter algum tipo de controle sobre o universo interacional acionado pelo projeto. Os mecanismos de controle, o "gerenciamento" das colaborações e intervenções do público, o "governo" das condutas pressupõem a configuração de um dispositivo midiático de participação, cujo conceito pretendemos aqui explorar.

Palavras-chave: transmidiação; cultura participativa; dispositivo.

Abstract: Media dispositive of participation in transmedia interactions - Transmedia is a production model oriented by associated content distribution through several media and technological

1 Este artigo é uma versão revista do texto apresentado ao Grupo de Trabalho Práticas Interacionais e Linguagens do XXIV Encontro Anual da Compós, UnB - UCB, Brasília, de 09 a 12 de junho de 2015. Também é parte de uma pesquisa realizada no âmbito do Observatório Ibero-americano de Ficção Televisiva (Obitel Brasil). 
platforms, whose articulation depends on the engagement proposed to the consumer. On one hand, transmedia actions follow the audience inclination to correlate media content and, on the other, to comment, share and interfere directly on the products offered in different platforms. This participation demands, however, being aligned with certain corporate, communicative targets. In order to succeed, transmedia producers aim to induce the audience and keep some sort of control over the interactional universe triggered by the project. The controlling mechanisms, the "management" of audience's collaboration and interferences, and the "government" of manners presuppose a participatory media device setting, which is the concept this paper intends to explore.

Keywords: transmedia production; participatory media device; content distribution.

\section{Introdução: apresentação do contexto e do problema}

Desafiada pelo cenário de convergência de meios, a televisão também aderiu à lógica da transmidiação, um modelo de produção orientado pela distribuição em distintas mídias e plataformas tecnológicas de conteúdos associados entre si e cuja articulação depende do engajamento proposto ao consumidor de mídias (FECHINE, 2014). Na transmidiação, os projetos são desenvolvidos em torno de uma mídia de referência a partir da qual os conteúdos se propagam e se expandem graças à incorporação de outras plataformas em sua cadeia criativa. No caso da televisão, as estratégias transmídias envolvem, principalmente, a disponibilização na internet de conteúdos complementares ou correlacionados/associados aos seus programas por meio de portais corporativos, sites oficiais ou perfis em redes sociais. Explorando tecnologias digitais interativas, tais estratégias contam com os consumidores de mídia como agentes fundamentais tanto na articulação desses conteúdos transmídias quanto na sua própria realização, já que muitos deles demandam uma "resposta" ou dependem de uma intervenção direta dos fãs espectadores. Os projetos transmídia estão ancorados em estratégias e práticas interacionais estimuladas pelos meios digitais e esse apelo à participação consiste justamente no seu diferencial em relação a outras formas de circulação de conteúdos entre mídias. Por isso, podem ser pensados, ao mesmo tempo, tanto como estímulo quanto como resultado da chamada cultura participativa. Apoiados nas ideias de Jenkins (2008), designamos como cultura participativa o cenário e o conjunto variado de possibilidades abertas aos consumidores de maior acesso, produção e colocação em circulação de conteúdos midiáticos, a partir da digitalização e convergência dos meios.

A realização de um projeto transmídia depende, antes de tudo, da disposição do público para buscar e correlacionar os conteúdos midiáticos ofertados em diferentes plataformas. Depende também da sua capacidade para se conectar de maneiras novas (por meio das redes sociais, sobretudo), moldando ativamente a circulação desse conteúdo e desenvolvendo habilidades tanto para filtrar quanto para se envolver amplamente com os produtos espalhados nas distintas mídias pelos produtores (FECHINE, 2013). A participação proposta pelo projeto transmídia é parte constitutiva de suas estratégias e, 
como tal, precisa estar em sintonia com o alcance de determinados objetivos. No caso da televisão, é óbvio supor que tais estratégias buscam, em última instância, despertar o interesse e promover positivamente seus programas, garantindo a predileção e a fidelização do público aos seus produtos. Para que suas estratégias obtenham êxito, os produtores transmídias se esforçam, evidentemente, para influenciar as ações e comportamentos do público, mantendo algum tipo de controle sobre o universo interacional acionado pelo projeto. Os mecanismos de controle, o "gerenciamento" das colaborações e intervenções do público, o "governo" das condutas, das permissões e interdições pressupõem a configuração do que denominamos de dispositivo midiático de participação, cujo conceito pretendemos aqui explorar como parte do percurso mais amplo, e ainda em curso, de estudo das estratégias e práticas interacionais transmídias (FECHINE, 2013, 2014; FECHINE et al., 2013).

\section{Sobre dispositivos}

A noção de dispositivo como instância de controle ganha relevo na obra de Michel Foucault (2001, 2008, 2009) e, a partir dela, é reoperada por autores como Giorgio Agamben (2009). Em Foucault, a ideia de dispositivo está intrinsecamente ligada a de governamentalidade e, ambas, são indissociáveis do exercício do poder nas suas mais distintas formas de manifestação. Originalmente, o termo "governamentalidade" foi utilizado por Foucault (2008) para designar o poder baseado na transferência, na alienação ou na representação da vontade dos indivíduos pelos aparelhos do Estado instaurado no século XVIII. Ao usar o termo, ele se referia não apenas às "técnicas de disciplina" do corpo pelo Estado, mas também ao "governo das almas" forjado pela Igreja.

Em pouco tempo, o termo, que foi empregado por Foucault em um sentido historicamente bem circunscrito às "técnicas de governo" subjacentes à formação do Estado moderno, adquire um significado mais geral e abstrato associado à descrição dos modos de "gestão da vida". Passa a ser usado, então, para tratar um leque variado de relações (micropoderes) - relações entre pais/filhos, alunos/professores, indivíduo/ poder público, população/medicina etc. O conceito é dotado de tanta plasticidade que acaba por atravessar e se diluir na descrição dos sistemas que regem imanentemente a conduta dos indivíduos (o biopoder). No pensamento foucaultiano, o termo dispositivo nomeia aquilo em que e por meio do qual se realiza uma atividade de governo, ou seja, diz respeito aos meios pelos quais se governa.

Partindo do pensamento do filósofo francês, Agamben (2009, p. 40) dá ainda mais amplitude ao conceito e descreve o dispositivo como sendo "qualquer coisa que tenha de algum modo a capacidade de capturar, orientar, determinar, interceptar, modelar, controlar e assegurar os gestos, as condutas, as opiniões e os discursos dos seres viventes". Para isso, postula Agamben (2009), os dispositivos implicam sempre processos de subjetivação, 
ou seja, produzem o seu próprio sujeito pela ação mesma de sua operação. Estão, por isso mesmo, ligados diretamente aos aparatos para "governo" das vontades e determinação de condutas, constituição e a internalização de regras e, como consequência de tudo isso, o estabelecimento de controles. É a partir dessa derivação da ideia de dispositivo como uma instância na qual se institui mecanismos de controle do real, ainda que sob a sombra do seu inerente descontrole, que a noção chega também ao cinema documentário e se aproxima mais do sentido que aqui nos interessa.

Nos estudos recentes de cinema, o termo "dispositivo" tem sido empregado, com a assumida inspiração foucaultiana, para tratar de procedimentos, métodos ou "protocolos" de filmagem que implicam determinação de "modos de agir", em algum tipo de "modelagem" do real, de direcionamento e controle dos comportamentos, condutas, discursos de sujeitos históricos e reais envolvidos na situação de representação. Descreve, em outras palavras, "o conjunto de regras que organizam o filme impondo-lhe limites espaço-temporais, controles e descontroles" (MIGLIORIN, 2005, p. 2). Nesses filmesdispositivo, são as "regras", ou a "estrutura", criadas pelo diretor, que dão origem e determinam a representação. Segundo Migliorin (2005), a criação de dispositivos se propõe a filmar o que ainda não existe e só existirá quando ele (o dispositivo) entrar em ação.

Nesses filmes, acrescenta Consuelo Lins (2007, p. 48), "o diretor não filma nem dirige, mas concebe um jogo, distribui cartas, determina regras, escolhe jogadores, fornece câmeras, transporte, comida. Provê o necessário e sai de campo". Cria, portanto, as condições nas quais emerge a própria representação. Um exemplo de filme-dispositivo é Rua de Mão Dupla, de Cao Guimarães. Nele, o diretor convida pessoas que não se conhecem para trocar de casa durante vinte e quatro horas. Nesse período, os participantes são provocados a tentar descobrir quem morava na casa que ocuparão por vinte e quatro horas (sexo, características, gostos etc.). Cada participante filma o que quiser na casa do outro e, depois, dá um depoimento no qual fala do que "descobriu" (imaginou) do dono da casa e da experiência vivida. É este o dispositivo a partir do qual se dá, nas palavras de Migliorin (2005), a "ativação do real", do mesmo modo que ocorre em muitos outros documentários contemporâneos batizados de filmes-dispositivo.

Segundo Migliorin (2008, p. 30), o dispositivo fílmico pode ser pensado também como "a criação de um campo de atualizações possíveis, de acontecimentos, indivíduos, pensamentos, gestos, sons e imagens". Depende da atuação e das relações dos indivíduos, mas, ao mesmo tempo, é também o próprio dispositivo que estabelece as possibilidades e condições das interações. Todo dispositivo pressupõe, portanto, uma dimensão de controle, ditada pelas regras e limites estabelecidos pelo seu criador, e outra dimensão de abertura determinada pelas possibilidades de atuação e de interação entre os seus agentes (participantes convidados, atores, equipe técnica etc.). Entre permissões e interdições, "fechamento" (zonas de controle) e "abertura" (margem de liberdade), cada dispositivo aciona um universo interacional que depende não apenas das "regras", mas também 
das características dos agentes e da materialidade que ele assume. Dessa forma, cada um deles assume sua configuração específica. Para indicar as especificidades desse tipo de dispositivo no âmbito das ações transmídias, recorremos à ideia de dispositivo midiático de participação, do qual trataremos a seguir.

\section{O dispositivo midiático de participação}

A criação de um dispositivo midiático de participação é uma precondição para o desenvolvimento de um projeto transmídia. Nesse tipo de produção, a expressão designa as condições, os mecanismos e os procedimentos técnico-expressivos por meio dos quais se busca governar o agenciamento e a participação dos agentes frente aos conteúdos transmídias. As condições a que nos referimos aqui dizem respeito às crenças, regras e ritos que, em uma determinada sociedade e em um determinado momento histórico, são impostos aos indivíduos por fatores exteriores. Nesse caso específico, essas condições correspondem aos valores e apelos da própria cultura participativa. Podemos considerar como mecanismos todos os meios pelos quais se dá, possibilita-se e se controla os agenciamentos do público no projeto. Os procedimentos técnico-expressivos, por sua vez, podem ser identificados com o emprego de determinados aparatos tecnológicos em conformidade com as características da mídia que orienta as estratégias.

Como no dispositivo fílmico, este que nos interessa também pressupõe a definição de "regras" e a delimitação de um espaço-tempo, no qual ocorrem as interações propostas pelo projeto. Estabelece o campo de participação. Igualmente, o dispositivo midiático de participação demanda variadas formas de ação ou intervenção dos indivíduos, mas, por meio de suas permissões e interdições, modula sua atuação. Da mesma maneira que o dispositivo fílmico estabelece limites para as relações no momento da filmagem, o dispositivo em questão também impõe condicionamentos à participação, o que também é próprio a esse tipo de dispositivo, justamente por acionar uma participação do público e, ao mesmo tempo, transitar entre o controle e o descontrole em relação às próprias ações a que ele (dispositivo) dá lugar. Toda convocação à participação envolve riscos e, por mais que estes sejam calculados, há sempre a possibilidade do inesperado romper a previsibilidade da regra. Por isso, é parte do dispositivo a existência de mecanismos de vigilância (emprego de ferramentas de monitoramento, "filtragem", moderações em redes sociais etc.).

A distinção essencial entre o dispositivo fílmico, que nos serve aqui de referência, em relação ao dispositivo midiático de participação reside nesses mecanismos de controle. Por ser um aparato de produção, o dispositivo cria, segundo Migliorin (2005), uma situação na qual os indivíduos são convidados a agir. No filme-dispositivo, o interesse está justamente no acontecimento, na possibilidade de captar o que é contingente, de produzir situações que o diretor não tem - nem quer - como prever e controlar, e a partir das quais 
se dá, depois, o gesto criativo da montagem. No dispositivo fílmico, o acaso, o desvio, todo tipo de escapatória são desejáveis, pois está fundado no que Jean-Louis Comolli chama de "risco do real" (apud MIGLIORIN, 2008, p. 22), o que, no caso do documentário, produz as representações não roteirizáveis e, frequentemente, próximas de uma ficcionalização do real. O criador propõe as peças e regras do "jogo" e a sorte está lançada.

No dispositivo midiático de participação, o que se almeja é, ao contrário, regular as colaborações e intervenções do público, esforçando-se para, de algum modo, domar o acaso e o contingente que lhes são inerentes. Por isso, a natureza desse tipo de dispositivo é marcada por uma inevitável tensão entre limitar e liberar a participação. Sua operação exige, em função disso, espaços nos quais pode se dar a vigilância e a regulação que garantem o governo da participação. É nesses espaços, instituídos pelos projetos e incorporados às estratégias transmídias, que o dispositivo manifesta sua materialidade. Se, no filmedispositivo, essa materialidade pode ser associada às condições mesmas de filmagem (locações, aparato técnico, cronograma etc.), no projeto transmídia, podemos identificá-la a todos os aparatos e às situações nos quais é proposta uma participação "regrada" do público.

Para entender como se materializa um dispositivo de participação midiática, dirigimos nosso olhar para as ações transmídias na teledramaturgia da Rede Globo. A escolha justifica-se: a conceituação aqui desenvolvida surgiu da observação e categorização, entre 2012-2014, das estratégias de transmidiação da teledramaturgia da emissora como parte de um projeto coletivo de pesquisa abrigado pelo Observatório Ibero-americano de Ficção Televisiva (FECHINE et al., 2013). Explorando o uso de plataformas e suportes variados, esse dispositivo midiático de participação se materializa, nas ações transmídias da Globo, em seus perfis em redes sociais digitais, como Facebook, Twitter e Instagram, e no portal Gshow, que abriga os sites oficiais de todos os programas de entretenimento da referida rede televisiva.

É importante ressaltar, no entanto, que o dispositivo não corresponde nem às plataformas (portais, Facebook, Twitter etc.) nem às estratégias. Corresponde precisamente à operação destas umas por meio daquelas - uma operação a partir da qual se ativa e se regula a "resposta" às estratégias e o agenciamento dos conteúdos disponibilizados nas plataformas. Vamos ver então, ainda que brevemente, como esse apelo à participação ocorre a partir da observação de Malhação, um seriado que está no ar desde 1995 e que, por ser dirigido ao público jovem, tem explorado de modo mais intenso a transmidiação. Ao voltar o nosso olhar para o seriado, consideramos que, por ser dirigido a adolescentes e jovens, a sujeição e a internalização das "regras" do dispositivo poderiam ser mais facilmente observadas em Malhação. Como, nessa etapa da reflexão, o interesse inicial foi tão somente exemplificar e evidenciar o potencial do dispositivo midiático de participação para "governar" a participação, a escolha nos pareceu pertinente. Reconhecemos, no entanto, que, para flagrar as aberturas, "escapatórias" e "desvios", que também são constitutivas desse tipo de dispositivo, é preciso alargar o olhar para outros 
produtos da ficção seriada da Globo. Para o objetivo assumido neste artigo, limitamos a observação ao seriado Malhação durante uma semana, entre 15 e 19 de dezembro de 2014.

\section{- Malhação no Gshow}

O portal Gshow concentra informações sobre os programas da Central Globo de Produção (novelas, seriados, programas de auditório, enfim, produções de entretenimento da emissora). Reúne e dá acesso aos sites das novelas que estão no ar e de outras que estiveram recentemente. Nele, são lançadas para o consumidor variadas possibilidades de participação a partir de enquetes, quiz, games, comentários relacionados aos programas da TV Globo. Apelos e procedimentos semelhantes podem ser observados nos sites oficiais de cada produto. No site de Malhação, um dos mais movimentados, é fácil flagrar o funcionamento da "regulação" da participação operada pelo dispositivo. No menu do site de Malhação, por exemplo, existe uma seção chamada "Você em Malhação". Nela, a produção estimula os consumidores a enviarem vídeos, com até três minutos, cantando, dançando ou interpretando algo a partir de um tema proposto. Os vídeos enviados são avaliados e um participante é selecionado pela produção para participar de um capítulo junto com o elenco da trama.

Ainda na seção "Você em Malhação", existe a possibilidade de assistir ao material recebido pela produção. Dessa forma, é possível assistir aos vídeos postados, avaliá-los e comentá-los. Quando se assiste aos vídeos, percebe-se que Malhação cria possibilidade para que as pessoas, além de verem os vídeos postados, possam classificá-los em três categorias pré-estabelecidas (Zerou a Web, Own *_* e \#Chorei). Como exemplo, destacamos o vídeo postado por Renata Cristina Lopes Miccelli, que estava na página principal classificado nas três categorias possíveis. No vídeo, percebe-se que de fato foram seguidas as recomendações dadas pela produção de Malhação. Renata diz: “Oi, meu nome é Renata. Tenho 17 anos. Sou de Curitiba, no Paraná. E, como o tema deste mês é sobre amizade, vou dedicar essa música a uma grande amiga minha que eu perdi em 2014. Ela faz muita falta. Então, esta vai ser para ela. Mudaram as estações/ Nada mudou/ Mas eu sei que alguma coisa aconteceu/Tá tudo assim tão diferente/ Se lembra quando a gente/ Chegou um dia a acreditar/ Que tudo era pra sempre/ Sem saber/ Que o pra sempre/ Sempre acaba. Brigada". O vídeo segue adequadamente o "roteiro" ou as "regras" propostas pelo dispositivo de participação.

Evidentemente, vídeos que fujam do que foi estabelecido pela produção, nem sequer são publicados. Para garantir o controle sobre os conteúdos enviados, o regulamento do "Você em Malhação" deixa claro que "[...] a Globo poderá utilizar qualquer método na escolha do participante para a ação interativa em referência" (MALHAÇÃO, 2015, informação eletrônica). Afirma ainda que a decisão da comissão julgadora é soberana. Além de exigir, das pessoas que enviam suas produções, autorização para uso de imagem no site e na TV, restringe a participação de pessoas que representem ou trabalhem em empresas concorrentes e veta ações que contrariem os interesses da produção, ficando a critério da emissora a decisão de usar o vídeo e/ou contar com a participação do escolhido na novela. 
Outro exemplo que mostra esse direcionamento da participação está no espaço chamado "Malhação Sonhos". Nessa parte do site, os fãs podem interagir com a produção e entre si com comentários sobre as cenas que estão no ar. Durante a exibição da série, a produção posta comentários sobre as cenas e, a partir desse momento, qualquer pessoa que estiver inscrita no site pode entrar na conversa. No entanto, quando alguém envia um comentário, não é possível visualizar imediatamente sua postagem, pois, antes, ele deve passar por um "filtro" de controle. Só depois, o responsável pela postagem recebe uma notificação de que seu conteúdo foi selecionado e estará em "Malhação no Ar". A produção assume claramente que há um controle na divulgação, mas essa "regulação" não inibe a participação daqueles que se consideram fãs e que, para terem seus conteúdos divulgados, esforçam-se para atender às expectativas da emissora.

\section{- Malhação e perfis em redes sociais}

A Rede Globo tem perfis oficiais no Facebook, Twitter e Instagram para divulgação geral de informações, realização de promoções e convocação à interação. Por possuírem um apelo mais direto à participação, há programas, no entanto, com páginas exclusivas no Facebook, como é o caso de Malhação. A página de Malhação é utilizada, predominantemente, para estimular os espectadores a acompanharem a exibição da TV e a visitarem o site, o que é feito por meio de antecipação de cenas e informações sobre a novela ou pela postagem de comentários sobre os personagens, a trama ou elenco. Um recurso muito frequente é a postagem de vídeos de atores convocando o público para acessar a cenas já exibidas, com convocações do seguinte teor: "E aí, galera, tudo bem? Não. Vocês assistiram ao capítulo de ontem? Foi babado, correria e confusão, né não? Ó, mas, se você perdeu, não fica triste. Entra no site que tem tudo. Mas ó, é rapidinho, hein, que daqui a pouco começa Malhação". Todas as postagens da produção são amplamente comentadas pelos consumidores, mas, no período em que foi feita uma observação sistemática da página, não encontramos nenhum comentário dissonante. Pelo contrário. Foram frequentes comentários como "Quero ver" ou "Quem num vai perder curte aqui" em resposta ao convite dos produtores para assistirem ao programa.

Outra iniciativa de sucesso em Malhação no Facebook é a utilização de hashtags, marcações em comum, para os consumidores utilizarem durante o dia. Existe uma postagem em que a produção sugere a hashtag \#Forçajeff, de forma que os consumidores da rede social utilizem a mesma expressão para ajudar o jovem. Há outra em que a produção sugere que os fãs usem a hashtag \#queroacamparemmalhacao. Nos comentários, é possível encontrar consumidores já utilizando a expressão e, no compartilhamento das publicações, muitos seguem a orientação e usam as expressões. No Twitter, essas estratégias e práticas interacionais se repetem e também é fácil observar os fãs utilizando as hashtags recomendadas pela produção. Entre elas, destaca-se a hashtag \#Malhação, cuja utilização se tornou um modo de identificação dos fãs. Além dos tweets da emissora em que a tag é 
utilizada, observamos, por parte dos seguidores e espectadores de Malhação, o emprego de construções do tipo "Acabou :: \#Malhação" ou "u.u vendo \#Malhação".

No Instagram, o procedimento mais comum é a publicação de imagens de cenas de programas da emissora, mas há também a possibilidade de comentar, curtir conteúdos criados pela emissora por meio dos perfis Rede Globo, Malhação e The Voice Brasil. Aqui, também, os comentários aos conteúdos das postagens estão sempre em sintonia com os objetivos e direcionamentos dos produtores. Quando a equipe de Malhação faz, por exemplo, uma postagem destacando as maldades da vilã Roberta, os fãs invariavelmente curtem e respondem com comentários de endosso do tipo "é uma cobra", "maquiavélica" e "do mal". É curioso observar que esse alinhamento com os conteúdos disponibilizados pela emissora ocorre inclusive nos perfis criados pelos próprios fãs em espaços que podemos considerar como não oficiais. Em uma busca online a partir do termo "Malhação", encontramos diversos Tumblrs com imagens de cenas e personagens do seriado com o mesmo caráter promocional.

Localizamos, ainda, no Facebook muitas páginas em referência aos personagens e à série como, por exemplo, "Karina Irônica" ou "Pedro Irônico". Embora o nome nos remeta a algo que subverterá o sentido de Malhação e dos personagens, as páginas compartilham o sentido proposto pelo enunciador. Na página "Tomtom Irônica", as postagens tratam do resumo dos capítulos, trazem fotos e compartilhamentos de publicações do site de Malhação. A responsável pela página convida os consumidores a assistirem ao programa dizendo: "Oi, gente. Não vão perder Malhação hoje, né? Fiquem todos ligadinhos"; e, por fim, pergunta se os seguidores querem resumo do episódio. Operando a partir do dispositivo de participação, os fãs se comportam, de modo geral, como se fossem parte da produção de Malhação. É provavelmente por isso que não se tem notícia de medidas da Globo para retirar seus conteúdos do ar, nem reclamações dos fãs quanto a proibições diretas impostas pela empresa. Há, no entanto, um acompanhamento contínuo de todas as ações dos fãs, e prova disso é a página "alerta redes sociais" dentro do site institucional da Globo. Nele, são constantemente atualizadas notícias sobre perfis falsos de atores, apresentadores e programas da empresa.

\section{Considerações finais}

Os procedimentos observados em Malhação evidenciam algumas tensões inerentes ao funcionamento do dispositivo de participação operado pela Rede Globo. Nos espaços oficiais abertos à colaboração e intervenção dos espectadores como parte de suas ações transmídias, a emissora monitora e filtra com cuidado as colaborações e intervenções do público, assumindo, nos termos foucaultianos, uma postura ainda excessivamente disciplinadora² mesmo no interior do dispositivo de participação. No entanto, o êxito na regulação da participação não depende tanto dos mecanismos de controle direto (filtros,

2 Para Foucault, o poder disciplinar manifesta-se, sobretudo, por meio de técnicas das instituições punitivas (colégios, quartéis etc.), mas, podemos associá-lo, aqui, numa acepção mais ampla, aos mecanismos de controle direto dos comportamentos em determinados espaços; no caso, os sites e perfis institucionais. 
moderadores, monitoramento etc.) dos conteúdos produzidos pelos fãs e seguidores, pois, sempre que se torna evidente o papel sancionador da produção, suas estratégias perdem eficácia. Como postulou Agamben (2009, p. 46), todo dispositivo implica um processo de subjetivação sem o qual ele não pode funcionar como "máquina de governo" no jogo do poder. Nisso reside sua maior eficácia. Nos dispositivos midiáticos de participação, esse processo de subjetivação pode ser associado aos afetos e todo tipo de projeção, identificação, envolvimento emocional, construídos frente ao universo ficcional, a partir, inclusive, das próprias ações transmídias.

Observamos aqui, portanto, um curioso processo de determinação recíproca: o dispositivo tanto depende quanto promove um "governo" das vontades, graças ao qual, neste caso específico, os consumidores agem, geralmente, em conformidade com o que se espera deles, movidos por gratificações decorrentes das diversas formas de reconhecimento e pertencimento envolvidas na participação. Com suas "respostas" esperadas e previsíveis às estratégias transmídias, os consumidores não apenas viabilizam, mas agregam valor aos produtos a partir de seus agenciamentos e suas intervenções. Brasil e Migliorin (2010, p. 29) lembram que, hoje, as empresas tornaram esses diversos modos de colaboração em uma grife "que se forja em palavras de ordem de liberdade: escreva, crie, divulgue, atue, participe, interaja". Eles apontam ainda a capacidade que as empresas desenvolveram de capitalizar a participação do público ao mesmo tempo em que obtém, com o estímulo para que ele mostre suas necessidades e desejos, informações que continuarão a nortear as estratégias sustentadas pelos dispositivos.

Como os demais, o dispositivo midiático de participação - não é demais insistir - não tem por função prescrever ou interditar, mas regular. Para Foucault (2008, p. 63), "um dispositivo de segurança só poderá funcionar bem [...] justamente se lhe for dada certa coisa que é a liberdade". Por isso, tão importante quanto o controle almejado pelas "regras" inerentes ao dispositivo é a liberdade de ação a partir do que elas próprias (as regras) propõem. Essa autonomia frente às regras pode dar lugar, em outro extremo, a "desvios" e "escapatórias" que subvertem completamente as estratégias comunicativas e objetivos empresariais. É preciso, no entanto, considerar essas condutas não esperadas e essas "respostas" indesejáveis como variável constitutiva do próprio dispositivo midiático de participação, já que depende dele sua ativação. Por isso mesmo, são tão frequentes iniciativas como a criação por fãs de sites, blogs, perfis em redes sociais destinados a programas, personagens ou atores, como vimos em alguns exemplos de Malhação. Evidentemente, como essas iniciativas estão fora dos espaços oficiais, os produtores não podem acionar seus mecanismos diretos de controle. Mas o dispositivo precisa levá-las em conta para garantir o "governo" da participação. O esforço dos produtores transmídias por "governar" mesmo aquilo sobre o qual não se pode ter controle é bem parecido com a alegoria do barco empregada por Foucault para explicar as várias dimensões envolvidas no ato de governar: 
O que é governar um barco? É encarregar-se dos marinheiros, mas é também encarregar-se do navio, da carga; governar um barco também é levar em conta os ventos, os escolhos, as tempestades, as intempéries. E é esse estabelecimento da relação dos marinheiros com o navio que se tem de salvar, com a carga que se tem de levar ao porto, e as relações de tudo isso com todos esses acontecimentos que são os ventos, os escolhos, as tempestades, é o estabelecimento dessa relação que caracteriza o governo de um barco (FOUCAULT, 2008, p. 129).

No "governo" do "barco" transmídia, é preciso considerar, igualmente, os "ventos", "tempestades" e "intempéries" decorrentes do estímulo a uma participação que, uma vez acionada, navega solta no "mar". A produção de conteúdos pelos fãs em espaços não oficiais (apropriações) impõe ao projeto transmídia, do mesmo modo, variáveis sobre as quais não se tem controle, mas que precisam ser consideradas na rota de "navegação". Se o dispositivo do qual estamos tratando aqui corresponde, em suma, às condições, aos mecanismos e aos procedimentos técnico-expressivos por meio dos quais se busca o "governo" da audiência, ele deve incorporar também, em seu funcionamento, os "desvios" e o "descontrole" inerentes à liberdade de ação subjacente no convite à participação. É isso, precisamente, que torna tão complexo - e muitas vezes contraditório - o universo interacional acionado por ações transmídias, especialmente quando estas partem de empresas de comunicação, como a Rede Globo, habituadas à concentração de poder e a um domínio rigoroso sobre seus conteúdos.

Yvana Fechine é professora do Departamento de Comunicação Social/Programa de Pós-graduação em Comunicação da Universidade Federal de Pernambuco e pesquisadora do Obitel Brasil.

yvanafechine@hotmail.com

Diego Gouveia é professor do Núcleo de Design do Centro Acadêmico do Agreste da Universidade Federal de Pernambuco e pesquisador do Obitel Brasil.

dgmgouveia@gmail.com

\section{Referências}

AGAMBEN, G. O que é o contemporâneo? e outros ensaios. Trad. Vinícius N. Honesko. Chapecó: Argos, 2009.

BRASIL, A.; MIGLIORIN, C. Biopolítica do amar: generalização de uma prática, limites de um conceito. Revista Galáxia, São Paulo, n. 20, p. 84-94, dez. 2010. Disponível em: <http://revistas. pucsp.br/index.php/galaxia/article/viewFile/3280/3292>. Acesso em: 20 jan. 2015. 
FECHINE, Y. Televisão transmídia: conceituações em torno de novas estratégias e práticas interacionais da TV. In: ENCONTRO ANUAL DA COMPÓS (Associação Nacional dos Programas de Pós-graduação em Comunicação), 22., 2013, Salvador. Anais... Salvador: UFBA, 2013.

Transmidiação e cultura participativa: pensando as práticas de agenciamento dos fãs de telenovelas brasileiras. In: ENCONTRO ANUAL DA COMPÓS (Associação Nacional dos Programas de Pós-graduação em Comunicação), 23., 2014, Belém. Anais... Belém: UFPA, 2014.

FECHINE, Y.; GOUVEIA, D.; ALMEIDA, C.; COSTA, M.; ESTEVÃO, F. Como pensar os conteúdos transmídias na teledramaturgia brasileira? Uma proposta de abordagem a partir das telenovelas da Globo. In: LOPES, M. I. V. (Org.). Estratégias de Transmidiação na Ficção Televisiva Brasileira. Porto Alegre: Sulina, 2013.

FOUCAULT, M. Microfísica do poder. 16. ed. Rio de Janeiro: Graal, 2001.

História da sexualidade I: a vontade de saber. 19 ed. Rio de Janeiro: Graal, 2009.

Segurança, território e população. São Paulo: Martins Fontes, 2008.

JENKINS, H. Textual poachers: television fans and participatory culture. New York: Routledge, 1992.

Transmedia Storytelling. In: Technology Review, 2003. Disponível em: $\leq$ http://www. technologyreview.com/news/401760/transmedia-storytelling/page/3/ . Acesso em: 02 fev. 2009.

Cultura da convergência. Trad. S. Alexandria. São Paulo: Aleph, 2008.

LINS, C. O filme-dispositivo no documentário brasileiro contemporâneo. In: Sobre fazer documentários. Vários autores. São Paulo: Itaú Cultural, 2007.

MALHAÇÃO. Disponível em: <http://gshow.globo.com/novelas/malhacao/2014/voce-emmalhacao/ noticia/2014/06/voce-em-malhacao-leia-o-regulamento.html $\geq$. Acesso em: 20 jan. 2015.

MIGLIORIN, C. Eu sou aquele que está de saída: dispositivo, experiência e biopolítica no documentário contemporâneo. 2008. Tese (Doutorado em Comunicação) - Universidade Federal do Rio de Janeiro, CFCH/ECO, Rio de Janeiro, 2008.

. Dispositivo como estratégia narrativa. Revista Acadêmica de Cinema - Digitagrama, n. 3, Rio de Janeiro: Universidade Estácio de Sá, 2005. 